\section{Safety issues of tooth whitening using peroxide-based materials}

IN BRIEF

- Provides current scientific information on safety issues relating to tooth whitening that involves the use of peroxide compounds and chlorine dioxide as the active ingredient.

Y. Li*1 and L. Greenwall ${ }^{2}$

VERIFIABLE CPD PAPER
- Describes types of tooth whitening modalities and the mechanisms of action of peroxide-based materials.

- Discusses sources of the safety concerns and potential risks associated with tooth whitening.

In-office tooth whitening using hydrogen peroxide $\left(\mathrm{H}_{2} \mathrm{O}_{2}\right)$ has been practised in dentistry without significant safety concerns for more than a century. While few disputes exist regarding the efficacy of peroxide-based at-home whitening since its first introduction in 1989, its safety has been the cause of controversy and concern. This article reviews and discusses safety issues of tooth whitening using peroxide-based materials, including biological properties and toxicology of $\mathrm{H}_{2} \mathrm{O}_{2}$ use of chlorine dioxide, safety studies on tooth whitening, and clinical considerations of its use. Data accumulated during the last two decades demonstrate that, when used properly, peroxide-based tooth whitening is safe and effective. The most commonly seen side effects are tooth sensitivity and gingival irritation, which are usually mild to moderate and transient. So far there is no evidence of significant health risks associated with tooth whitening; however, potential adverse effects can occur with inappropriate application, abuse, or the use of inappropriate whitening products. With the knowledge on peroxide-based whitening materials and the recognition of potential adverse effects associated with the procedure, dental professionals are able to formulate an effective and safe tooth whitening regimen for individual patients to achieve maximal benefits while minimising potential risks.

The use of hydrogen peroxide $\left(\mathrm{H}_{2} \mathrm{O}_{2}\right)$ for tooth whitening can be traced back more than a century. ${ }^{1}$ The procedure was primarily practised only in dental practices until 1989 when Haywood and Heymann first introduced at-home tooth whitening. ${ }^{2}$ Due to its effectiveness and the increasing quest for whiter teeth by the general population, tooth bleaching has become a popular aesthetic dental procedure and an integrated part of dental practice.

The terms of tooth whitening and tooth bleaching have been used interchangeably both in the literature and clinical practice. The International Organization for Standardization (ISO) defines tooth bleaching as 'removal of intrinsic or acquired discolorations of natural teeth through the use of chemicals, sometimes in combination with the application of auxiliary means. ${ }^{3}$

'Professor of Restorative Dentistry/Professor of Microbiology and Molecular Genetics/Director of Center for Dental Research, Center for Dental Research, Loma Linda University Schools of Dentistry, 24,876 Taylor Street, Loma Linda, California 92350, USA: ${ }^{2}$ Private Practice, London

*Correspondence to: Yiming Li; Email: yli@llu.edu

\section{Refereed Paper}

Accepted 13 March 2013

DOI: 10.1038/sj.bdj.2013.629

${ }^{\circ}$ British Dental Journal 2013; 215: 29-34
It is an oxidative process that alters the light absorbing or light reflecting nature of the tooth structure, increasing its perception of whiteness. On the other hand, whitening is the process resulting in the material becoming similar in colour to a preferred or standard white regardless of the means used. In dental practice, mechanical approaches, such as polishing and brushing with abrasive-based prophylactic pastes and toothpastes, are used to remove extrinsic tooth surface stains subsequently providing a whitening effect. There are few safety concerns with these mechanical whitening materials, and this paper will review and discuss only tooth whitening using peroxide-based agents, therefore, the term bleaching instead of whitening is used throughout the remainder of the text.

\section{ACTIVE INGREDIENTS AND APPLICATION MODALITIES}

Current tooth bleaching materials almost exclusively use carbamide peroxide and $\mathrm{H}_{2} \mathrm{O}_{2}$ as active ingredients in tooth bleaching regardless of in-office or at-home uses. ${ }^{4-6}$ Chemically, carbamide peroxide is composed of approximately 3.5 parts of $\mathrm{H}_{2} \mathrm{O}_{2}$ and 6.5 parts of urea, so that a bleaching gel of $10 \%$ carbamide peroxide provides around 3.5\% $\mathrm{H}_{2} \mathrm{O}_{2}$. Therefore, the true active ingredient for tooth bleaching is $\mathrm{H}_{2} \mathrm{O}_{2}$. Typically, $\mathrm{H}_{2} \mathrm{O}_{2}$ concentrations used for in-office bleaching range from $25 \%$ to $40 \%$, while at-home formulations contain 3 to $9 \% \mathrm{H}_{2} \mathrm{O}_{2}$; however, there has been a trend in recent years to elevate the $\mathrm{H}_{2} \mathrm{O}_{2}$ concentration in products for at-home bleaching, and those of up to 15\% $\mathrm{H}_{2} \mathrm{O}_{2}$ have now become available directly to consumers for home use.

The at-home tooth bleaching regimen was originally intended to be part of a complete dental procedure. The dentist conducts dental examinations to ensure no contraindications for bleaching, prescribes a treatment regimen, and monitors the progress for appropriate whitening effects without significant side effects. ${ }^{6,7}$ However, the advantages of at-home bleaching, including ease of use, low cost, convenience and whitening efficacy, quickly promoted the growth of over-the-counter (OTC) bleaching products for home use.

\section{Chlorine dioxide tooth whitening agents}

Nowadays there are a wide variety of at-home bleaching products available to 
consumers in various forms including custom or preformed trays, brushes, or strips. Recent years have also shown an increase in procedures promising in-office results performed in non-dental settings such as mall kiosks, spas and cruise ships. ${ }^{6,8}$ While many OTC products have demonstrated safety and efficacy for consumers, other unregulated and unresearched materials and methods may potentially cause irreversible damage if used on a long-term basis. The products in cruise ships and beauty spas commonly use chlorine dioxide as the active ingredient positioned as a 'safer' alternative to hydrogen peroxide while avoiding local and state legislations regarding the use of hydrogen peroxide. In truth, these chlorine dioxide products are more harmful, having little if any safety studies and commonly coming with a $\mathrm{pH}$ of 2 to 3. The chlorine dioxide at 0.5\% concentration applied to the teeth for 20 minutes in a chair side procedure with gingival protection applied by a beauty therapist has been shown to strip the enamel off the teeth (Fig. 1), reduce the enamel lustre (Fig. 2) and cause sensitivity. In the case depicted in Figure 1 the material used was chlorine dioxide and this was applied for 20 minutes onto the surface of the anterior teeth. The patient was then given a gel to take home and paint onto the teeth. Figure 1 shows how the enamel surface of the anterior teeth appears rough and has lost the appearance of lustre compared to that of the premolars and molars, which did not receive the treatment and appear normal. The left side of the teeth (not shown) showed the same appearance. The teeth became sensitive to cold, felt rough to the touch and easily picked up stain.

As a result of chlorine dioxide use, teeth are more prone to re-staining, develop a rough surface and become extremely sensitive. Further, the reduced enamel lustre appears irreversible, and there appears to lack effective measures to resolve the damage other than costly restorative means. ${ }^{9}$

\section{MECHANISMS OF TOOTH BLEACHING}

While tooth bleaching has become popular and millions of people have received the treatment during the last two decades, the mechanisms of tooth bleaching remain yet to be fully understood..$^{6,10}$ The

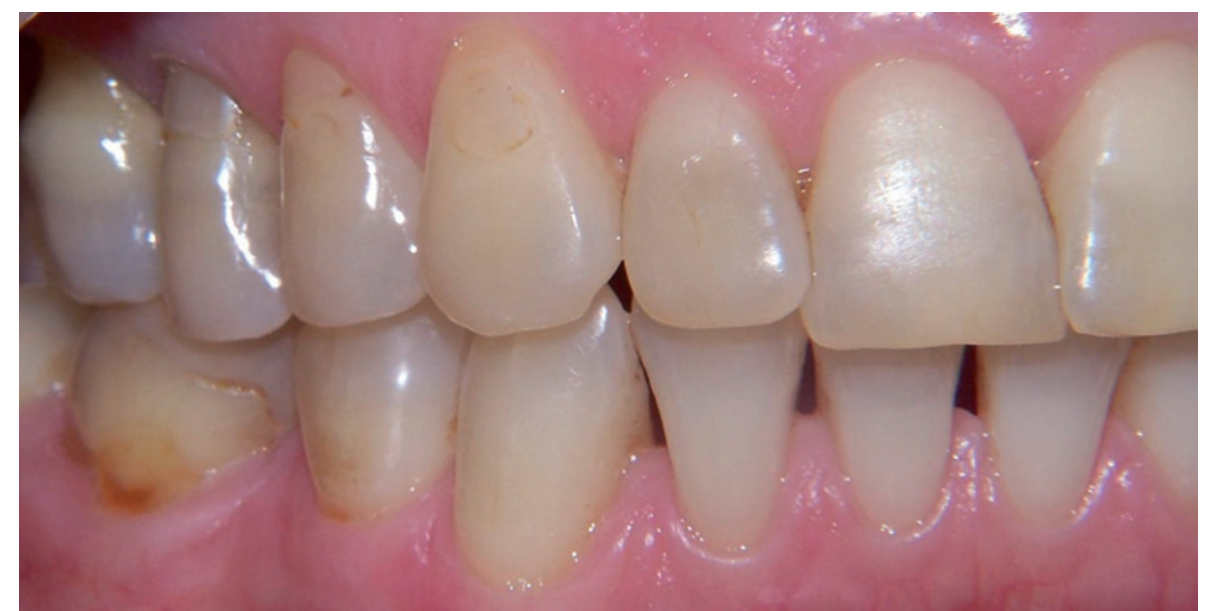

Fig. 1 Right side of maxillary teeth of a patient who had teeth whitened on a cruise using chlorine dioxide based materials

generally accepted mechanism involved in tooth bleaching is similar to that in textile and paper bleaching: free radicals, produced by $\mathrm{H}_{2} \mathrm{O}_{2}$, interact with pigment molecules to produce a whitening effect. It is hypothesised that $\mathrm{H}_{2} \mathrm{O}_{2}$ in bleaching gel produces free radicals while diffusing through enamel and dentine, breaking double bonds of pigment molecules and changing the pigment molecule configuration and/or size. Such changes alter the optical properties of tooth structure, creating the perception of a whiter tooth colour. This theory is also plausible in explaining the commonly observed shade rebounding shortly after the bleaching treatment, probably due to the reformation of the double bonds.

Besides the bleaching effect by free radicals, it is possible that there are nonbleaching effects during the bleaching process that help enhance the whitening effect, including the cleansing of the tooth surface. Enamel dehydration during the bleaching process may also result in a temporary whitening effect since enamel dehydration alone is capable of producing a significant, visible tooth shade reduction. ${ }^{11}$ Such whitening effect dissipates upon the rehydration of the enamel.

Bleaching efficacy can be influenced by patient factors (for example, age, gender and initial tooth colour), the bleaching material used (for example, type of peroxide compound, peroxide concentration and other ingredients), and application method (for example, contact time, application frequency, enamel prophylaxis before bleaching treatment). These factors not only contribute to the bleaching

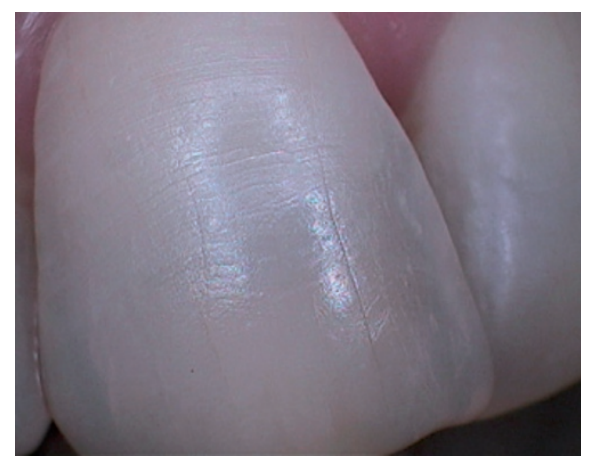

Fig. 2 Right maxillary central incisor showing the rough surface texture of the tooth following the application of the chlorine dioxide

efficacy but also affect the subsequent stability of the achieved bleaching efficacy. ${ }^{10-13}$ Among these factors, the contact time of the bleaching material to enamel the others. ${ }^{13}$

\section{SAFETY ISSUES OF TOOTH BLEACHING AND SOURCES OF CONCERNS}

Safety concerns with tooth bleaching were initially raised with the rapid growth of at-home bleaching. The primary source of the safety concerns with tooth bleaching originated from the known toxicity of $\mathrm{H}_{2} \mathrm{O}_{2}$, especially its capability to produce free radicals, including hydroxyl radicals. Studies indicate that oxidative reactions of free radicals with proteins, lipids and nucleic acids, with the consequential potential pathological damage, may be associated with ageing, stroke and other degenerative diseases. ${ }^{14-16}$ The oxidative reactions and subsequent damage in cells by free radicals are believed to be the major mechanisms responsible for the observed toxicity of $\mathrm{H}_{2} \mathrm{O}_{2}$. Consequently, surface appears to be more influential than 


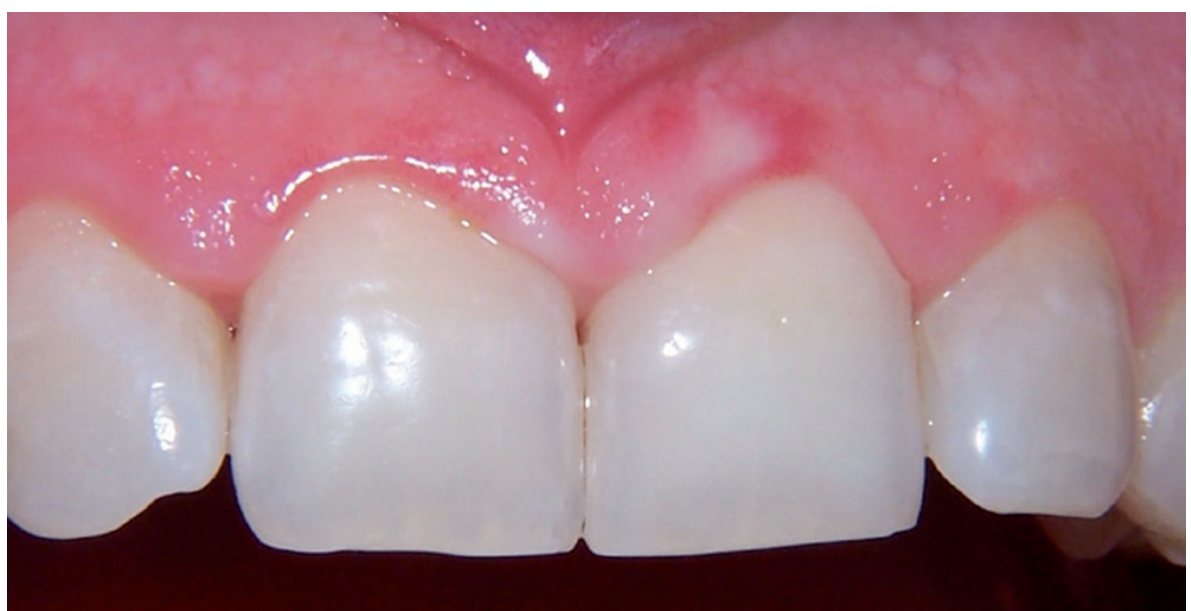

Fig. 3 Tissue burn which the patient experienced as a result of the contact of gel to gingival tissue during the power bleaching procedure

there were safety concerns with potential systemic adverse effects if the bleaching gel were to be ingested as well as local adverse effects on enamel, pulp and gingiva because of the direct contact of the gel with the tissues.,17-19 The safety controversies over the peroxide-based tooth bleaching prompted not only scientific deliberations but also legal challenges to their use in dentistry. ${ }^{4,6,18-20}$

When used appropriately the exposure to $\mathrm{H}_{2} \mathrm{O}_{2}$ from bleaching treatment is minimal. During the in-office bleaching, the soft tissues are adequately protected using barrier materials and the gel is removed at the end of bleaching; little, if any, gel is left behind for possible ingestion. For at-home bleaching, the approximate carbamide peroxide dose for each at-home application was $90 \mathrm{mg}^{2}$ A later report estimated an average of $502 \mathrm{mg}$ bleaching gel per application used clinically for ten maxillary teeth (six anterior teeth plus four bicuspids). ${ }^{4}$ When both arches are being bleached, the average amount of the gel used is approximately $1.0 \mathrm{~g}$. For a bleaching gel containing 10\% carbamide peroxide, the exposure dose would be $100 \mathrm{mg}$ per application. Dahl and Becher ${ }^{21}$ estimated that approximately $10 \%$ of the applied bleaching gel may be consumed during the application. Therefore, for an individual of $60 \mathrm{~kg}$ body weight who receives at-home bleaching for both arches once daily, the exposure to the bleaching gel can be calculated at $1.67 \mathrm{mg} / \mathrm{kg} /$ day, and the exposure to carbamide peroxide through a gel containing 10\% carbamide peroxide will be $0.167 \mathrm{mg} / \mathrm{kg} /$ day. A gel of $10 \%$ carbamide peroxide contains approximately 3.5\% $\mathrm{H}_{2} \mathrm{O}_{2}$; consequently, the estimated $\mathrm{H}_{2} \mathrm{O}_{2}$ exposure is $0.058 \mathrm{mg} /$ $\mathrm{kg} /$ day, or $3.48 \mathrm{mg} \mathrm{H}_{2} \mathrm{O}_{2}$ per day for an adult of $60 \mathrm{~kg}$ body weight.

The human body is equipped with various defensive mechanisms at cellular and tissue levels to prevent potential damage of $\mathrm{H}_{2} \mathrm{O}_{2}$ to cells and to repair any damage sustained. Enzymes such as catalase, SOD, peroxidase and selenium-dependent glutathione peroxidase, which exist widely in body fluids and tissues, including saliva, effectively metabolise $\mathrm{H}_{2} \mathrm{O}_{2} \cdot{ }^{22}$ In fact, salivary peroxidase has been suggested to be the most important and effective defence in the human body against the potential adverse effects of $\mathrm{H}_{2} \mathrm{O}_{2} \cdot{ }^{23} \mathrm{~A}$ study on infants, juveniles, adults, and adults with impaired salivary flow found rapid decomposition of $\mathrm{H}_{2} \mathrm{O}_{2}$ in dentifrices. ${ }^{24}$ After one-minute brushing with one gram of dentifrice, $<2 \%$ of the pre-brushing dose of $\mathrm{H}_{2} \mathrm{O}_{2}$ (30 mg) was detectable in the oral cavity of these subjects. This indicates that within one minute, the oral cavity is capable of eliminating $>8$ times of $\mathrm{H}_{2} \mathrm{O}_{2}$ used in a bleaching session with a gel of 10\% carbamide peroxide. Therefore, if used appropriately the $\mathrm{H}_{2} \mathrm{O}_{2}$ exposure from bleaching is minimal; furthermore, it is essentially limited to the oral cavity and is incapable of reaching a systemic level to induce toxicity because of the effective metabolic defensive mechanisms.

With research efforts and accumulation of data over the last two decades, safety concerns with potential systemic toxicities of peroxide-based tooth bleaching have largely diminished. However, research efforts have continued to determine the safety of home use tooth bleaching, especially on the risk assessment, clinical relevancy of in vitro findings, and regulations and international standards., ${ }^{34-39}$ In Europe a new directive has been outlined for all countries in the $\mathrm{EU}^{30}$ and the United Kingdom enacted legislation to comply with the directive in October 2012. ${ }^{31-34}$ This directive states that up to $6 \%$ hydrogen peroxide may be given to consumers for tooth bleaching treatments at-home only after an examination and first treatment by a dentist. The British Dental Bleaching Society is trying to include the prohibition of the use of chlorine dioxide for bleaching teeth within the amendments to the directive.

\section{POTENTIAL RISKS ASSOCIATED WITH TOOTH BLEACHING}

While the systemic risks are no longer a primary safety issue for tooth bleaching, it is important to recognise its potential local adverse effects. In-office bleaching uses gels of high $\mathrm{H}_{2} \mathrm{O}_{2}$ concentrations that can cause tissue burns upon contact. This effect is shown in Figure 3 in which a gel of 25\% $\mathrm{H}_{2} \mathrm{O}_{2}$ was applied to the teeth. In this case, the soft tissues were isolated with a light cure dam. The tissue ulceration is a chemical burn, which is sometimes referred to as 'tissue blanching'. The best treatment for this is to act immediately by applying water on the area to neutralise the damage. If caught early the tissue changes to red after a minute or so then returns to the pink colour. However if the power bleach gel is left on the soft tissue and gingiva for too long the ulceration takes much longer to resolve and the patient may suffer pain from the blistering for 1 to 2 weeks. The ulceration can be single or multiple. Vitamin E has been recommended for applying to the ulceration to help healing.

Some home-use bleaching requires continuous direct contact of the gel to enamel surface for up to 7 or 8 hours (overnight). The enamel-gel contact may also be repeated within the same day or daily for an extended period. When applied by consumers at home, unintended direct contact of the bleaching gel to gingiva may occur, and for some at-home systems such as strips, the gingival contact is inevitable. In addition, a user undertaking at-home bleaching may overuse the product that 
may aggravate the tissue due to extended contact with the gel. Tooth sensitivity and gingival irritation, though mostly transient and dissipating with time and which can be mitigated with proper usage protocol, are well documented adverse effects associated with tooth bleaching.

Commonly known local risks associated with tooth bleaching include primarily tooth sensitivity, gingival irritation as well as potential adverse effects on enamel and restorative materials. ${ }^{17-19,35-37}$ The level of the risk depends on the quality of the bleaching gel, the techniques used, and the individual's response to the bleaching treatment.

\section{Tooth sensitivity}

Tooth sensitivity to temperature changes is a commonly observed clinical side effect during or after the bleaching of vital teeth, with an incidence up to 50\%. ${ }^{37}$ The sensation of the sensitivity often occurs during the early stages of treatment and usually persists for two to three days, and it is usually mild to moderate and transient. ${ }^{37-39}$. It appears that the sensitivity peaks on the third day of treatment, likely because this is when there is maximum saturation of oxygen inside the pulp..$^{40}$ The development of tooth sensitivity does not appear to be related to the patient's age or sex, defective restorations, enamel-cementum abrasion or the dental arch treated; however, the risk increases in patients who change the bleaching gel more than once a day. ${ }^{37}$

The mechanisms of tooth sensitivity are not fully understood; however, it is believed that the sensation is possibly an indication of pulp response to $\mathrm{H}_{2} \mathrm{O}_{2}$ and free radicals. ${ }^{10,13}$ The assumption is largely based on in vitro studies showing that $\mathrm{H}_{2} \mathrm{O}_{2}$ in bleaching gel applied on the enamel surface is capable of penetrating through the enamel and dentine and reaching the pulp chamber. ${ }^{38-47}$ In general, these studies show that $<30 \mu \mathrm{g}$ of $\mathrm{H}_{2} \mathrm{O}_{2}$ may reach the dental pulp after applying gels of up to $12 \% \mathrm{H}_{2} \mathrm{O}_{2}$ on the enamel surface for up to 7 hours. The amount of $\mathrm{H}_{2} \mathrm{O}_{2}$ detected in the pulp chamber tends to increase with the time and $\mathrm{H}_{2} \mathrm{O}_{2}$ concentration in the gel, but not proportionally. It has been suggested that an amount of $50,000 \mu \mathrm{g} \mathrm{H}_{2} \mathrm{O}_{2}$ is needed to inhibit pulpal enzymes, so that the detected amount of $\mathrm{H}_{2} \mathrm{O}_{2}$ penetrating into the pulp chamber in tooth bleaching does not appear
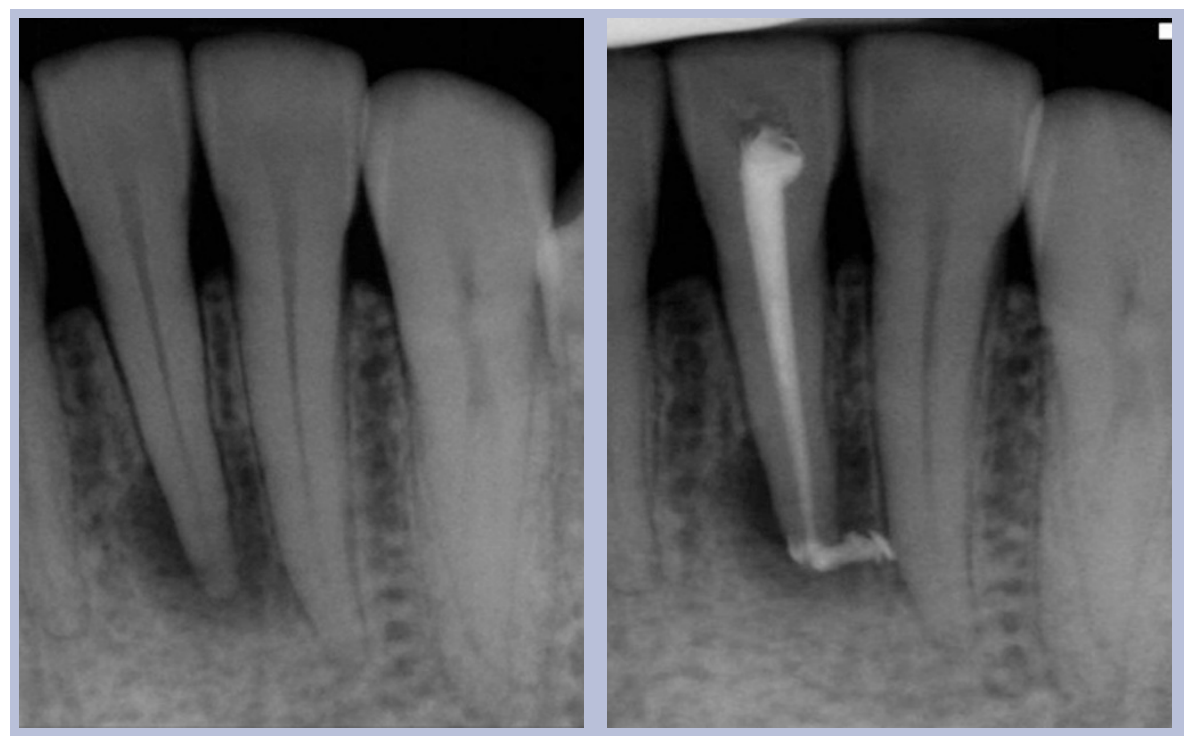

Fig. 4 Periapical radiographs showing radiolucency on the lower left central incisor

to cause significant damage to pulp tissues. However, there is a lack of in vivo research on this topic, and long-term effects of such $\mathrm{H}_{2} \mathrm{O}_{2}$ exposure on pulp are yet to be determined. Therefore, practitioners should exercise caution and bleaching should not be performed on teeth with caries, exposed dentine, or defective restorations.

Tooth bleaching has been used for children and adolescents with success in most cases. ${ }^{48}$ So far there has been only one report of significant enamel damage in a teenager. ${ }^{49}$ However, practitioners are advised to take extra caution because of newly erupted teeth; closer monitoring and emphasis of compliance should be exercised to reduce the risk of abuse tendency. For practitioners in areas covered by the EU directive, it is imperative to observe the rule that tooth bleaching of individuals younger than 18 years of age is prohibited. ${ }^{31-34}$

In addition, it is essential to assess any discoloured tooth for vitality. This is done by measuring the response to cold, normally with ethyl chloride and with electric pulp testing. A periapical radiograph is essential to assess that the discoloured tooth does not have an existing periapical radioluscency and is free from pathology. If a tooth has untreated periapical radiolucency there is a potential for a flare up of pain during the bleaching treatment as can be seen in Figure 4. In this case, the patient had a power tooth bleaching treatment first, followed by home treatment. After three days of home bleaching the patient reported extreme pain. The radiograph shown in Figure 4a was taken at this stage and demonstrated the existence of a lower periapical radiolucency associated with the tooth. The patient needed to have a root canal treatment to heal the lesion and thought that the pain was due to the initial power bleaching procedure. It is the responsibility of the treating dentist to take a radiograph of any discoloured tooth to exclude the possibility of a radiolucency being present. The patient received endodontic treatment (Fig. 4b); there is a puff of root canal cement extruding through the apex of the tooth.

\section{Gingival irritation}

Gingival irritation is also a commonly observed clinical side effect in tooth bleaching. It may or may not occur with tooth sensitivity; the patient may be unable to differentiate gingival irritation from tooth sensitivity. ${ }^{50-53}$ The reported incidence of gingival irritation for at-home bleaching ranges from 5 to $50 \%$ in most studies. It is usually mild to moderate, occurring two to three days after using the bleaching gel and then dissipating. For most patients gingival irritation is tolerable and is not a barrier to completing the treatment. When using the tray systems, an ill-fitted tray is usually the primary cause for the irritation. The problem is usually resolved by properly trimming the tray. The risk of gingival irritation appears to be related to the $\mathrm{H}_{2} \mathrm{O}_{2}$ concentration in the gel and the contact of the gel to the gingiva.

Gingival irritation associated with inoffice bleaching is mostly caused by a leaky 
or failed gingival barrier protection ${ }^{46,47}$. The practitioner must check the barrier for signs of leakage, usually indicated by air bubbles, and the patient should be questioned for any discomfort during the bleaching treatment. The light cure barrier should cover all buccal gingival surfaces and there should be no visible pink gingiva showing. If tissue burn is detected (Fig. 3), the surface should be extensively rinsed with water until the whiteness is reduced. In more severe cases, a topical anaesthetic, limited movements and good oral hygiene will help the healing process. Vitamin E may be placed directly onto the surface of the chemical ulceration to help healing of the area..$^{54}$ In addition, the positioning of the light should not be too near the lips to prevent burning. The positioning of the bleaching light directly onto the retractor may cause the retractor to pull on the lower lip resulting in a tissue burn.

\section{Potential adverse effects on enamel}

The effect of bleaching on enamel has been evaluated primarily in three aspects: mineral loss, surface morphological changes, and alteration of surface microhardness; most enamel effect studies were conducted using in vitro systems. ${ }^{55-63}$ Overall data indicate that there is a loss of minerals during the bleaching treatment; however, this does not appear to constitute a significant risk because of the effective remineralisation mechanisms readily available in the oral cavity. Most scanning electron microscopy (SEM) and surface microhardness studies showed little or no changes of bleached enamel surface. On the other hand, several investigators reported alteration of enamel surfaces associated with bleaching. However, in most cases the observed alterations of enamel surface morphology varied among different products and were associated with products using acidic pre-rinse or gels of low $\mathrm{pH}$. In addition, studies have demonstrated that some soft drinks and fruit juices (for example, orange, lemon and apple) can cause demineralisation and alteration of enamel surface morphology comparable to or greater than those reported for bleaching treatment. A six-month clinical study reported that daily use of a bleaching gel containing 10\% carbamide peroxide for six months did not adversely affect the surface morphology of human enamel..$^{55}$
To date, there is no clinical evidence of adverse enamel effects in the dentist-monitored at-home whiteners. However, two clinical cases were reported on significant damage of enamel with the use of OTC tooth whitening products. ${ }^{49,64}$

\section{Potential adverse effect on restorations}

A relevant safety concern is the mercury release from amalgam restorations during and after the bleaching. ${ }^{65-69}$ There is little dispute on mercury release associated with bleaching; however, the reported amount of mercury release varies greatly. The issue on potential health implication of released mercury remains controversial and requires further research. Because of the known toxicity of mercury, as a general rule it is not advisable to perform bleaching on patients whose teeth are extensively restored with amalgams.

While the adverse effects of tooth bleaching on restorative materials are not considered as direct health risks, the consequences can be significant to the quality and longevity of the restoration. Numerous studies have reported that tooth bleaching may adversely affect physical and/or chemical properties of restorative materials, including increased surface roughness, crack development, marginal breakdown, release of metallic ions, and decreases in tooth-to-restoration bond strength. ${ }^{68-71}$ The adverse effects of bleaching on bonding strength have been well documented. A plausible mechanism is the inhibition of polymerisation of bonding agent by residual oxygen formed during the bleaching. Similar effects are also applicable to other resin-based restorative materials that require in situ polymerisation. The post-bleaching inhibitory effects on the polymerisation dissipate with the time, and an interval of two weeks is found to be adequate to avoid such adverse effects.

\section{SUMMARY}

In-office tooth bleaching has been a part of dental practice for many years. With the data accumulated over the last two decades, at-home bleaching has also become an accepted and integrated procedure in dentistry. Accumulated data indicate no significant, long-term health risks associated with professional at-home tooth bleaching using 10\% carbamide peroxide gels, which is equivalent to $3.5 \% \mathrm{H}_{2} \mathrm{O}_{2}$. Therefore, when used appropriately, tooth bleaching is safe and effective.

As with any dental procedures, tooth bleaching involves risks. An appropriate usage protocol can effectively mitigate the potential risks. Tooth sensitivity and gingival irritation can occur in a significant portion of the patients, although in most cases they are mild to moderate and transient. When gels of high $\mathrm{H}_{2} \mathrm{O}_{2}$ concentrations, such as those for in-office bleaching, are used without adequate gingival protection, severe mucosal damage can occur. Such a risk can be prevented by using adequate gingival protection. Although rare, significant adverse effects are possible with inappropriate application, abuse, or the use of inappropriate at-home bleaching products. $\mathrm{H}_{2} \mathrm{O}_{2}$ is capable of producing various toxicological effects; practitioners need to recognise potential risks and excise appropriately to mitigate adverse consequences.

So far, few data are available on the safety of OTC at-home bleaching that simulates the intended application mode of these products. The safety of bleaching performed at mall kiosks, salons, spas and cruise ships is of particular concern because the procedures are similar to inoffice bleaching but performed by individuals with no formal dental training.

To minimise potential risks and maximise benefits, tooth bleaching under the supervision of a dental professional is strongly recommended. A recent case report illustrates the importance of the role of dental professionals in tooth bleaching treatment. ${ }^{72}$ A patient of dark tooth shade associated with dentinogenesis imperfecta received a carefully planned and executed bleaching regimen. It was a clinical success after a long-term (4.5 months), home use by the patient of a bleaching gel containing $14 \% \mathrm{H}_{2} \mathrm{O}_{2}$. The comprehensive clinical examination of the dentition and gingiva, custom designed at-home bleaching regimen, detailed instructions, and monitoring of the bleaching progress with adjustments helped to ensure the safe and satisfactory whitening outcome.

The preparation of this article was supported by Philips Oral Healthcare.

1. Fitch C P. Etiology of the discoloration of teeth.
Dent Cosmos $1861 ; 3$ : $133-136$.
2. Haywood V B, Heymann H O. Nightguard vital 
bleaching. Quintessence Int 1989; 20: 173-176.

3. International Organization for Standardization. Dentistry- Products for External Tooth Bleaching. ISO 28: 399. Geneva: ISO, 2011.

4. Li Y. Biological properties of peroxide-containing tooth whiteners. Food Chem Toxicol 1996; 34 : 887-904

5. Kihn P W. Vital tooth whitening. Dent Clin N Am 2007; 51: 319-331.

6. Li Y. Safety controversies in tooth bleaching. Dent Clin N Am 2011; 55: 255-263.

7. American Dental Association. Guidelines for the acceptance of peroxide-containing oral hygiene products. J Am Dent Assoc 1994; 125: 1140-1142.

8. American Dental Association. Tooth Whitening/ Bleaching: Treatment Considerations for Dentists and Their Patients. Council on Scientific Affairs, September 2010.

9. Greenwall L H. The Dangers Of Chlorine Dioxide Bleaching. Aesthetic Dentistry Today 2008; 2: 20-22.

10. Rotstein I, Li Y. Tooth Discoloration and Bleaching. Chapter 37. In Ingle J I, Bakland L K (eds) Endodontics. 6th ed. Toronto: BC Decker Inc., 2008

11. Tavares M, Stultz J, Newman M, Smith V, Kent R, Carpino $E_{1}$ Goodson J M. Light augments tooth whitening with peroxide. JAm Dent Assoc 2003; 134: 167-175.

12. Leonard R H. Efficacy, longevity, side effects, and patient perceptions of nightguard vital bleaching. Compend Contin Educ Dent 1998; 19: 766-781.

13. Li Y, Lee S, Cartwright S, Wilson A. Comparison of clinical efficacy and safety of three professional at-home tooth whitening systems. Compend Contin Educ Dent 2003; 24: 357-364.

14. Harman D. The aging process. Proc Natl Acad Sci U S A 1981; 78: 7124-7128.

15. Lutz W K. Endogenous genotoxic agents and processes as a basis of spontaneous carcinogenesis. Mutation Res 1990: 238: 287-295.

16. Floyd $R$ A. Role of oxygen free radicals in carcinogenesis and brain ischemia. FASEB J1990; 4: 2587-2597.

17. Li Y. Toxicological considerations of tooth bleaching using peroxide-containing agents. J Am Dent Assoc 1997: 128: 31S-36S.

18. Li Y. Peroxide-containing tooth whiteners: an update on safety. Compend Contin Educ Dent 2000; 21(Suppl 28): $\$ 4-S 9$

19. Li Y. The safety of peroxide-containing at-home tooth whiteners. Compend Contin Educ Dent 2003; 24: 384-389

20. Weiner M L, Freeman C, Trochimowicz $\mathrm{H}$ et al. 13-week drinking water toxicity study of hydrogen peroxide with 6-week recovery period in catalase-deficient mice. Food Chem Toxicol 2000; 38: $607-615$.

21. Dahl J E, Becher R. Acute toxicity of carbamide peroxide and a commercially available toothbleaching agent in rat. J Dent Res 1995: 74: $710-714$

22. ECETOX. Joint assessment of commodity chemicals No. 22- hydrogen peroxide. Brussels: European Center for Toxicology of Chemicals, 1993.

23. Carlsson J. Salivary peroxidase: an important part of our defense against oxygen toxicity. J Oral Pathol 1987; 16: 412-416.

24. Marshall M V, Gragg P P, Packman E W, Wright P B, Cancro L P. Hydrogen peroxide decomposition in the oral cavity. Am J Dent 2001; 14: 39-45.

25. Perdigão J. Dental whitening-revisiting the myths. Northwest Dent 2010; 89: 19-21, 23-26.

26. K. Maynard. Tooth whitening debate steps up a few shades. Br Dent J 2011; 211: 7 (News article).

27. Marques DN, da Mata A D, Silveira J M, Marques J R, Amaral J P, Guilherme N F. Hydrogen peroxide release kinetics into saliva from different whitening products: a double-blind, randomized clinical trial. Clin Oral Investig 2012; 16:155-163.

28. Sa $Y$, Wang $Z, M a X$ et al. Investigation of three home-applied bleaching agents on enamel structure and mechanical properties: an in situ study. J Biomed Opt 2012; 17: 035002.

29. Ward M, Felix H. A clinical evaluation comparing two $\mathrm{H} 2 \mathrm{O} 2$ concentrations used with a light-assisted chairside tooth whitening system. Compend Contin Educ Dent 2012; 33: 286-291.

30. Scientific Committee on Consumer Products. Opinion on Hydrogen Peroxide in Tooth Whitening Products Adopted by the SCCP during the $3^{\text {rd }}$ plenary meeting of 15 March 2005. http: // ec.europa.eu/health/ph_risk/committees/04_sccp/ docs/sccp_o_022.pdf, 2005.

31. The Council of The European Union. Council Directive 2011/84/EU, amending Directive 76/768/ EEC concerning cosmetic products. Official J Eur Union 2011; L283/36-38.

32. A new day for patients and consumers. Tooth whitening to be only carried out by dental practitioners. CED Press release of 21 September 2011/European directive 76/768/EEC, 2011

33. Council of European Dentists. CED Working Group Tooth Whitening, Working Group Mandate. CEDDOC-2011-066-E, 2011.

34. Department for Business, Innovation and Skills. Consumer Protection: The Cosmetic Products (Safety) (Amendment) Regulations 2012. Statutory Instruments. United Kingdom, 2012.

35. Haywood V B, Heymann H O. Nightguard vital bleaching: how safe is it? Quintessence Int 1991; 22: 515-523.

36. Li Y. Tooth bleaching using peroxide-containing agents: current status of safety issues. Compend Contin Educ Dent 1998: 19: 783-790.

37. Leonard R H, Haywood V B, Phillips C. Risk factors for developing tooth sensitivity and gingival irritation in nightguard vital bleaching. Quintessence Int 1997; 28: 527-534.

38. Jorgensen M G, Carroll W B. Incidence of tooth sensitivity after home whitening treatment. J Am Dent Assoc 2002: 133: 1076-1082.

39. Pohjola R M, Browning W D, Hackman S T, Myers M L, Downey M C. Sensitivity and tooth whitening agents. J Esthet Restor Dent 2002; 14: 85-91.

40. Matis B A, Mousa H N, Cochran M A, Eckert G J. Clinical evaluation of bleaching agents of different concentrations. Quintessence Int 2000: 31: 303-310

41. Bowles W H, Ugwuneri Z. Pulp chamber penetration of hydrogen peroxide following vital bleaching procedures. J Endodont 1987: 13: 375-377.

42. Cooper J, Bokmeyer T, Bowles W. Penetration of the pulp chamber by bleaching agents. J Endodont 1992: 18: 315-317.

43. Thitinanthapan $W$, Satamanont $P$, Vongsavan N In vitro penetration of the pulp chamber by three brands of carbamide peroxide. Esthet Dent 1999; 11: 259-264.

44. Slezak B, Santarpia P, Xu T, et al. Safety profile of a new liquid whitening gel. Compend Contin Educ Dent 2002; 23(Suppl 1): 4-11.

45. Pugh G, Zaidel L, Lin N, Stranick M, Bagley D. High levels of hydrogen peroxide in overnight toothwhitening formulas: effects on enamel and pulp. J Esthet Restor Dent 2005: 17: 40-45.

46. Sulieman M. An overview of bleaching techniques: 3. In-surgery or power bleaching. Dent Update 2005; 32: 101-104, 107-108.

47. Sulieman M, Addy M, Macdonald E, Rees JS. A safety study in vitro for the effects of an in-office bleaching system on the integrity of enamel and dentine. J Dent 2004; 32: 581-590.

48. Lee S S, Zhang W, Lee D H, Li Y. Tooth whitening in children and adolescents: a literature review. Pediatr Dent 2005; 27: 362-368.

49. Cubbon T, Ore D. Hard tissue and home tooth whiteners. CDS Review 1991; 84: 32-35.

50. Schulte J R, Morrissette D B, Gasior E J, Czajewski $M V$. Clinical changes in the gingiva as a result of at home bleaching. Compend Contin Educ Dent 1993; 14: 1362-1366.

51. Kugel G, Aboushala A, Zhou X, Gerlach R W. Daily use of whitening strips on tetracycline-stained teeth: comparative results after 2 months. Compend Contin Educ Dent 2002; 23: 29-34.

52. Gerlach R W, Zhou X: Comparative clinical efficacy of two professional bleaching systems. Compend Contin Educ Dent 2002; 23: 35-41.

53. Gerlach R W, Sagel P A, Jeffers M E, Zhou X Effect of peroxide concentration and brushing on whitening clinical response. Compend Contin Educ Dent 2002; 23: 16-21.

54. Burgess C. Topical vitamins. J Drugs Dermatol 2008 7(7 Suppl): S2-6.

55. Haywood V B, Leonard R H, Dickinson G L. Efficacy of six-months nightguard vital bleaching of tetracycline-stained teeth. J Esthet Dent 1997; 9: 13-19.

56. Bitter N C. A scanning electron microscope study of the long-term effect of bleaching agents on the enamel surface in vivo. Gen Dent 1998; 46: 84-88.

57. Potocnik I, Kosec L, Gaspersic D. Effect of 10\% carbamide peroxide bleaching gel on enamel microhardness, microstructure, and minera content. J Endodont 2000; 26: 203-206.

58. White D J, Kozak K M, Zoladz J R, Duschner H, Götz H. Peroxide interactions with hard tissues: effects on surface hardness and surface/subsurface ultrastructural properties. Compend Contin Educ Dent 2002; 23: 42-48.

59. Lopes G C, Bonissoni L, Baratieri L N, Vieira L C, Monteiro S Jr. Effect of bleaching agents on the hardness and morphology of enamel. J Esthet Restor Dent 2002; 14: 24-30.

60. Attin T, Schmidlin P R, Wegehaupt F, Wiegand A. Influence of study design on the impact of bleaching agents on dental enamel microhardness: A review. Dent Mater 2009; 25: 143-157.

61. Berger S B, Cavalli V, Martin A A et al. Effects of combined use of light irradiation and 35\% hydrogen peroxide for dental bleaching on human enamel mineral content. Photomed Laser Surg 2010; 28: 533-558

62. Li Q, Xu B T, Li R, Yu H, Wang Y N. Quantitative evaluation of colour regression and minera content change of bleached teeth. J Dent 2010 38: $253-260$

63. Sun L, Liang S, Wang Y S Z, Jiang T, Wang Y. Surface alteration of human tooth enamel subjected to acidic and neutral 30\% hydrogen peroxide. J Dent 2011; 39: 686-692.

64. Hammel S. Do-it-yourself tooth whitening is risky. US News and World Report 1998 April 20.

65. Rotstein I, Dogan H, Avron Y Shemesh H, Steinberg D. Mercury release from dental amalgam following treatment with 10\% carbamide peroxide in vitro. Oral Surg Oral Med Oral Pathol Oral Radiol Endod 2000; 89: 216-219.

66. Rotstein I, Avron Y, Shemesh H Dogan H, Mor C Steinberg D. Factors affecting mercury release from dental amalgam exposed to carbamide peroxide bleaching agent. Am J Dent 2004; 17: 347-350.

67. Al-Salehi S K. Effects of bleaching on mercury ion release from dental amalgam. J Dent Res 2009; 88: 239-243.

68. Attin T, Hannig C, Wiegand A, Attin R. Effect of bleaching on restorative materials and restorations- a systematic review. Dent Mater 2004; 20: 852-861.

69. Swift E J, Perdigao J. Effects of Bleaching on teeth and restorations. Compend Contin Educ Dent 1998; 19: 815-820.

70. Breschi L, Cadenaro M, Antoniolli F, Visintini $E_{1}$ Toledano M, Di Lenarda R. Extent of polymerization of dental bonding systems on bleached enamel. Am J Dent 2007: 20: 275-280.

71. Lima A F, Fonseca F M, Cavalcanti A N, Aguiar F H, Marchi G M. Effect of the diffusion of bleaching agents through enamel on dentin bonding at different depths. Am J Dent 2010; 23: 113-115.

72. Li Y. Commentary. Successful bleaching of teeth with dentinogenesis imperfecta discoloration: a case report. J Esthet Restor Dent 2011; 23: 1. 